\title{
Preparing port container terminals for the future: making the most of Intelligent Transport Systems (ITS)
}

\author{
K. McGinley \\ Department of Transport Engineering, Dublin Institute of Technology, \\ Ireland
}

\begin{abstract}
Governments and legislators all over the world view ports and terminals as vital infrastructure assets as they play a critical role in economic growth by attracting and generating trade. A port that does not have the ability to cope with rapidly advancing technologies will not be in a position to foster the development of the trade sector. Their ability to 'go green' by reducing their carbon footprint and by being more sensitive to environmental considerations is vital to their success.

The future is bringing increased demands for greater efficiency and for more sustainable designs in cargo handling technologies. Moreover, the scarcity of land is forcing port companies to realise higher area utilizations.

With the arrival of the next generation ultra-large Triple-E vessels carrying 18,000 TEU (twenty foot equivalent unit), it is important to investigate the opportunities to introduce innovation in the development of terminal operations and the logistics chain. The crucial terminal management problem is how to balance the integration of the current technology with the new state of the art technology such as the Intelligent Autonomous Vehicle (IAV). Although the IAV is not exactly new, what makes it different is that it does not require a guidance system such as rails or transponders set into the ground, to reach its destination. Traffic management and space optimization is a problem with the future development of container terminals. The problem can be solved by having a remote 'traffic control centre' directing vehicles to marshalling areas where the containers are handled by IAV's.
\end{abstract}


The challenge is to find innovative solutions to balance service requirements while integrating automated and non-automated cargo handling equipment in container terminals to ensure sustainability, safety and security.

Keywords: Intelligent Transport Systems, automated cargo handling equipment, non-automated cargo handling equipment, intelligent traffic management.

\section{Introduction}

In an ever-changing global scene, the maritime sector has had to take on many challenges. Due to the revolution of container shipping, the world economy has become more accessible with container throughput experiencing steady growth over the last fifty years. The international seaport business has changed radically within the space of several years. Globalisation has brought about changes in the structure of the world economy and the shipping and port industries have had to respond to the challenges. Opportunities have risen as a result of the structural changes which need to be exploited. Container shipping has become a competitive industry with shipping companies constantly looking for ways to improve profits.

Governments and legislators all over the world view ports and terminals as vital infrastructure assets as they play a critical role in economic growth by attracting and generating trade. A port that does not have the ability to cope with rapidly advancing technologies will not be in a position to foster the development of the trade sector. Their ability to 'go green' by reducing their carbon footprint and by being more sensitive to environmental considerations is vital to their success.

New port technology is essential to maintain economic growth and competitiveness. Developing new methods and technologies for ports has become an entirely separate economic activity. Until recently there was very little competition between ports, and port related costs were relatively insignificant in comparison to the high cost of ocean and inland transport. There was little incentive to improve port efficiency and effectiveness [1].

Most ports are competing with one another on a global scale and this has led the drive to improve port efficiency, lower cargo handling costs and integrate port services with other sectors of the global distribution network with regard to lowering emissions, safety and security. The maritime sector has considerable influence on the volumes and conditions of trade and the capacity for economic development. Developing new practices and technologies for ports has become vital for maintaining growth and generating trade. New port technology and capital investment in infrastructure is essential to maintaining economic growth and competitiveness. Global competition, intelligent transport systems (ITS) and communication technologies are continuously modifying the environment.

Ports play a vital role in economic growth by attracting and generating trade. A port that is not able to cope with rapidly advancing technologies will not be in a position to foster the development of the trade sector. Therefore, the development of new cargo handling technology is of paramount importance if a port is to succeed in implementing its economic role. 
The future is bringing increasing demands for greater efficiency and for more sustainable designs in cargo handling technologies. Moreover, the scarcity of land is forcing port companies to realise higher area utilizations.

With the arrival of the next generation ultra-large Triple-E vessels carrying $18,000 \mathrm{TEU}$, it is important to investigate the opportunities to introduce innovation in the development of terminal operations and the logistics chain.

The crucial terminal management problem is how to balance the integration of the current technology with the new state of the art technology such as the Intelligent Autonomous Vehicle (IAV). The problem can be solved by having a remote 'traffic control centre' directing vehicles to marshalling areas where the containers are handled by IAV's.

The challenge is to find innovative solutions to balance service requirements while integrating automated and non-automated cargo handling equipment to ensure sustainability, safety and security.

\section{North West Europe region}

The coastal region of North West Europe (NWE) stretching from Ireland to Rotterdam is of huge importance but despite this fact, few of its smaller and medium sized ports are able to keep pace with growth due to the immense pressure they are under. This pressure is due to increasing container traffic, the economic scarcity of land resources and escalating environmental concerns. These concerns are more referent to urban centre ports such as Dublin Port and other small ports in the NWE region.

The main problem in handling increasing levels of cargo is managing the internal traffic and optimizing space inside these ports. A new generation of cargo handling technology has been designed in the form of an IAV. The IAV is a clean, safe, intelligent vehicle, which will contribute to improving the traffic management and space optimization inside confined space by developing a clean, safe and intelligent transport system.

\section{Dublin Port}

Dublin is Ireland's biggest and busiest port and although volumes through the port were flat at 28.0 million gross for the third year (2013) running reflecting a continued weak consumer sentiment that prevailed throughout the year the port is looking to the future and how best to rebuild the economy. The port is crucial to the Irish economy as its function is to facilitate the movement of goods and people, in an efficient and cost effective manner. A Masterplan for the redevelopment of the port was approved in February 2012, setting out a framework to ultimately double capacity in the port to 60 million tonnes by 2040.

The port handles over $€ 35$ billion worth of trade every year and supports some 4,000 jobs locally. $90 \%$ of Irelands GDP is exported with $42 \%$ being handled through Dublin Port. The port offers multi-modal services with 
connections to Rotterdam, Antwerp, Le Havre, Felixstowe, Hamburg, Southampton and Liverpool, which are important strategic trading hubs.

Not only does Dublin Port Company compete with other ports on the island of Ireland but perhaps more importantly, it also operates a competitive business model within the port itself where eight terminals compete for business in the unitised sector. Unitised trade is comprised of Lo-Lo and Ro-Ro and accounts for over $80 \%$ of Dublin Port's trade [4].

In line with the Port Company's ambitions and growth forecasts, there is a need to optimise the use of Intelligent Transport System (ITS). Currently in Dublin Port, the movement of cargo is operated by shunter vehicles differing from Automated Guided Vehicles (AGVs) as in other international ports such as Rotterdam, Hamburg and Dusseldorf.

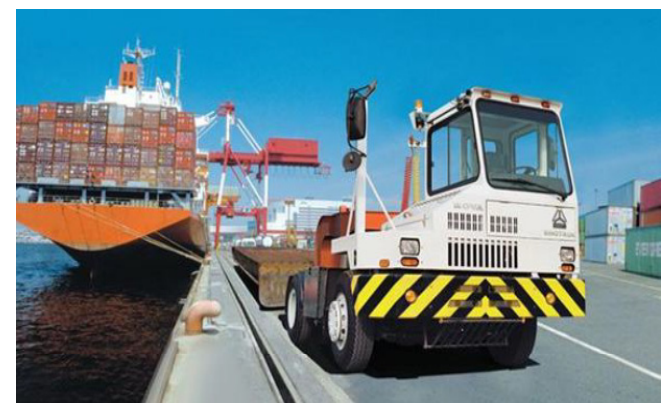

Figure 1: Shunter vehicle.

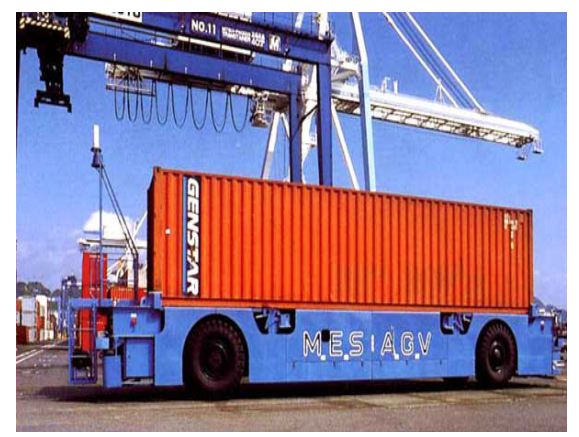

Figure 2: Automated Guided Vehicle (AGV).

\subsection{Dublin ferryport terminals (DFT)}

A case study was carried out in Dublin Ferryport Terminal (DFT), one of three container terminals in Dublin Port. DFT is conveniently located $3 \mathrm{~km}$ from Dublin city centre and $2 \mathrm{~km}$ from the entrance to the Dublin Port tunnel. The terminal recently completed an investment programme, which has seen its plant and machinery updated, the size of the terminal increased by $50 \%$ and the quay wall extended by 50 metres. 
Table 1 shows that DFT has the capacity for 450,000 TEU. It has two berths, which can facilitate up to three vessels at any one time. There are three ship-toshore gantry cranes where two have the ability to manoeuvre around corners allowing one, two or three cranes on one vessel at any one time. Secondary handling equipment is the cargo handling equipment for transporting containers for example shunter, straddle carrier, AGV's and reach stackers. Reefer points are located at the end of each stack where refrigerated containers can be plugged in.

Table 1: DFT Terminal profile.

\begin{tabular}{|l|l|}
\hline Capacity & 450,000 TEU \\
\hline Berths & $1 \times 360$ Metres @ 9.5 Meters Dept. \\
& $1 \times 180$ metres @ 11 Metres Dept. \\
\hline Ship - Shore Cranes & $3 \times 40 t$ STS ( 2 with full curve going \\
& facility) \\
\hline Secondary Handling Equipment & $8 \times 40$ trubber gantry cranes \\
& $1 \times 47$ treach stacker \\
& $4 \times$ empty container handlers \\
& $2 \times 18$ t fork lifts \\
\hline Reefers & 275 points \\
\hline
\end{tabular}

DFT provides container handling services to a range of third party customers as well as to its sister company Eucon. It also operates a high frequency container freight service from its base in Dublin Port to Rotterdam, Antwerp and Radicatel with connections to Cork and Belfast.

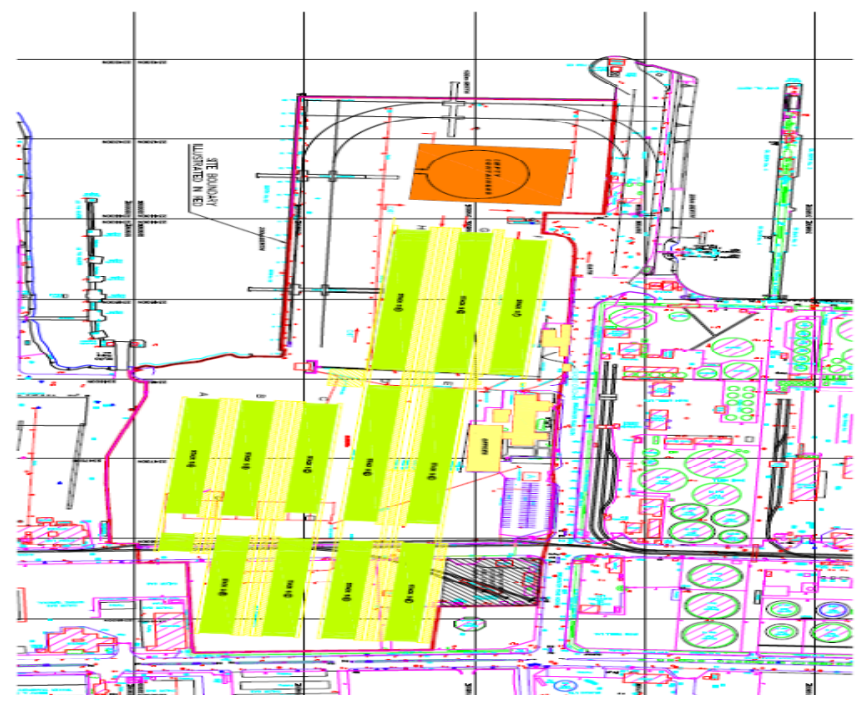

Figure 3: Layout of DFT. 
The layout of DFT is shown in figure 3. It has two berths and three quay cranes. The green tinted area indicates where full import and export containers are stored. The yellow area is the lane ways between the stacks, where the secondary handling equipment operates. The orange area shows where the locations of empty containers awaiting shipment are stored. This information was supplied by the management of DFT.

\section{Intelligent Transport Systems (ITS)}

Intelligent Transport Systems (ITS) is a wider term for the range of intelligent technologies that applies to transport vehicles and infrastructure. It delivers a host of advanced information and communication technologies to reduce emissions, improve safety, relieve congestion and enhance productivity. In the maritime sector it manages to coordinate and optimise space and manage traffic in a confined space, diminish vehicle emissions and improve air quality. ITS can significantly contribute to a cleaner, safer and more efficient transport system.

A new legal framework, Directive 2010/40/EU, was adopted on 7 July 2010 to accelerate the deployment of these innovative transport technologies across Europe. This Directive is an important instrument for the coordinated implementation of ITS in Europe. It aims to establish interoperable and seamless ITS services while leaving Member States the freedom to decide which systems to invest in. The aim is to reduce the EU's carbon footprint in transport by $60 \%$ before the year 2050 [2].

The common aim was to set up a framework to help EU ports to sustain development and raise the finance they need to invest in modern technology. Modernisation will help with attracting new business for ports and play a crucial part in solving real intermodal solutions for EU transport. In order to justify capital expenditure on facilities and equipment, ports need to achieve best international standards in areas such as cargo-handling and the overall cost of operations.

\subsection{Ireland's carbon footprint}

Under the Kyoto protocol, Ireland, as part of the EU, has agreed to limit its greenhouse gas (GHG) emissions to being no more than 13\% greater than 1990 levels, by 2012. Greenhouse gases are widely believed to be the cause of an increase in the average yearly temperature of the earth surface, contributing to melting of polar ice caps and adverse weather conditions worldwide. Despite major improvements in all sectors of its economy, Ireland has only managed to maintain levels at $23 \%$ greater than 1990 levels. Transport is a major determinant of the amount of $\mathrm{CO}_{2}$ emitted in Ireland, and transport companies continually strive to reduce their 'carbon footprint' [3]. 


\section{Intelligent Autonomous Vehicle (IAV)}

A new generation of cargo handling technology has been designed in the framework of Intelligent Transport for Dynamic Environment (InTraDE) an EU funded project to which Dublin Institute of Technology (DIT) is a partner, with Dublin Port Company as a sub partner. Participation in the project will contribute to improving the traffic management and space optimization inside confined space by developing a clean, safe and intelligent transport system such as an IAV [5].

The IAV is similar to the AGV but is technologically superior as it is battery operated making it more economically and environmentally efficient. In contrast to the AGV, the IAV does not have to follow designated routes embedded in the infrastructure to reach its destination.

The vehicle is an individual unit, which can also work in groups allowing it to form a platoon similar to a train with locomotives. The unit capacity of an IAV is one TEU (twenty-foot equivalent unit), two TEU, or one FEU (forty-foot equivalent unit); it can also accommodate a forty- five foot unit.

All four wheels have actuators and a failure in any of the wheels individually does not stop the vehicle from operating. The unit is battery operated and the wheels offer 360 degrees movement allowing the vehicle to move in any direction within a confined space.

The IAV is a multi-input, multi-data (MIMD) system equipped with several sensors, which will enable it to benefit from Geographical Positioning System (GPS), allowing it to move unmanned around port terminals, delivering containers to and from marshaling areas. Although the IAV is not exactly new, what makes it different is that it does not require a guidance system such as rails or transponders set into the ground to guide it around the terminal. Traffic management and space optimization is a problem with the future development of port terminals in NWE. The problem can be solved by having a remote 'traffic control centre' directing vehicles to marshalling areas where the containers are handled by IAV's.

Table 2: Battery specification of IAV.

\begin{tabular}{|l|l|}
\hline Working Temperature & $-10 C+40 C$ \\
\hline Storage Temperature & $-20 C+50 C$ \\
\hline
\end{tabular}

Table 3: Payload volume of $20 \mathrm{ft}$ container.

\begin{tabular}{|l|l|}
\hline Length & $12 \mathrm{M}$ \\
\hline Width & $2.4 \mathrm{M}$ \\
\hline Height & $2.6 \mathrm{M}$ \\
\hline Volume & $1360 \mathrm{CU}$ FT \\
\hline
\end{tabular}


Table 4: Summary of technical specifications of IAV.

\begin{tabular}{|l|l|}
\hline Weight (without load) & $6000 \mathrm{KG}$ \\
\hline Payload & $10000 \mathrm{KG}$ \\
\hline Wheels Diameter & $760 \mathrm{MM}$ \\
\hline Dimensions & $\mathrm{L}: 7 \mathrm{M}$ \\
& $W: 2.5 \mathrm{M}$ \\
\hline Height of Landing Try & $1.2 \mathrm{M}$ \\
\hline
\end{tabular}

Table 5: Characteristics of IAV.

\begin{tabular}{|l|c|}
\hline \multicolumn{1}{|c|}{4 Wheels } & Double Drive \& Steering \\
\hline Mass of Vehicle & 2225 Tons \\
\hline Height & $1300 \mathrm{MM}$ \\
\hline Width & $2500 \mathrm{MM}$ \\
\hline Length & $14000 \mathrm{MM}$ \\
\hline Wheel Diameter & $760 \mathrm{MM}$ \\
\hline Height under the Try & $1197 \mathrm{MM}$ \\
\hline Position of Center of Gravity & $0 \mathrm{MM}, 809 \mathrm{MM}, 0 \mathrm{MM}$ \\
\hline
\end{tabular}

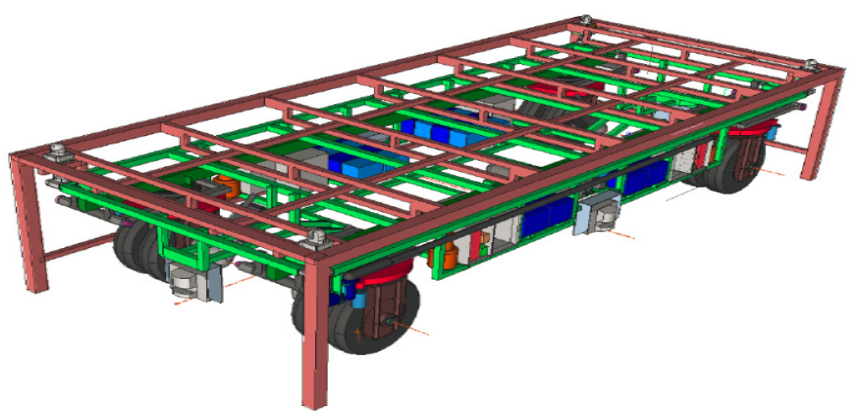

Figure 4: IAV Design.

\section{Conclusion}

ITS is one of the most economically practical, technical and environmentally friendly options for use in port container terminals. Using ITS is innovative and important because it offers the opportunity to respond to climate change while having the advantage of producing cheaper energy. It has a unique role when considering time saving and management improvements in port container terminals as time management and cost reduction have an undeniable effect on 
port existence and commercial benefits. Therefore, terminal operators should carefully consider their option when planning essential energy supplies. The IAV for example uses a renewable clean energy in contrast to fossil fuel based energy sources, which contaminate the lower layers of the troposphere.

The future is bringing increasing demands for greater efficiency and for more sustainable designs in cargo handling technologies. Moreover, the scarcity of land is forcing port companies to realize higher area utilizations. Terminal operators have the same objectives but they are also looking for cost reduction through decreased life cycle costs, energy consumption, maintenance etc. This is forcing terminal operators to invest in more sustainable, environmentally friendly and cost effective cargo handling equipment. The challenge is how to balance service requirements, costs and demands for sustainability.

\section{References}

[1] World Bank Port Reform Tool Kit/module 2. The Evolution of Ports in a Competitive World: http://rru.worldbank.org/Documents/Toolkits/ports_ $\bmod 2 . p d f$

[2] Transport: Action Plan and Directive. http://ec.europa.eu/transport/its/road/ action_plan/action_plan_en.htm

[3] Ireland's National Climate Change Strategy, 2007-2012, Environmental Protection Agency. www.environ.ie/en/Publications/Environment/.../File DownLoad,1861,en.pdf-Cached-Similar

[4] Dublin Port Company, Facts and Figures: www.padublin2013.com/dublinport-company/

[5] InTraDE, Intelligent Transportation for Dynamic Environment: http://www. intrade-nwe.eu/ 